Kattwinkel, J., Fanaroff, A., Cha, C., Fleming, D., Sosa, R., Crumrine, R., and Klaus, M. (1973). Controlled trial of continuous positive airway pressure (CPAP) in RDS and a simplified application by the nasal route. (Abst.) Pediatric Research, 7, 396.

Novogroder, M., MacKuanying, N., Eidelman, A. I., and Gartner, L. M. (1973). Nasopharyngeal ventilation in respiratory distress syndrome. Fournal of Pediatrics, 82, 1059.

Shannon, D. C., Lusser, M., Goldbatt, A., and Bunnel, J. B. (1972). The cyanotic infant. Heart disease or lung disease. New England Journal of Medicine, 287, 951.

G. Caliumi-Pellegrini, R. Agostino, M. Orzalesi, S. Nodari, G. Marzetti, P. G. Savignoni, and G. BUCCI*

Institute of Paediatrics, Neonatal Division, University of Rome Medical School, Rome, Italy.

*Correspondence to Dr. G. Bucci, Clinica Pediatrica Università, Viale Regina Elena 324, 00161 Roma, Italy.

\section{Phrenic nerve palsy treated by continuous positive pressure breathing by nasal cannula}

Early respiratory failure and death may occur in newborns with phrenic nerve palsy (Richard et al., 1957). We report 2 cases where newborn infants with respiratory failure due to this condition were successfully managed by continuous positive airway pressure (CPAP) breathing administered by nasal cannula.

\section{Methods}

Acid-base status and blood gases were determined on samples from the radial artery or the descending aorta by a micro-Astrup apparatus and a Clark-type microelectrode (Orzalesi et al., 1967). CPAP was administered by a twin nasal cannula and an apparatus as described by Caliumi-Pellegrini et al. (1974). The central venous pressure was measured with an umbilical venous catheter and a Hewlett Packard 1280C pressure transducer and $7819 \mathrm{~A}$ pressure monitor, visualized by a 7803A monitor scope. The tip of the catheter was located at the right atrial inlet by an internal electrocardioscopical method (Nodari, Agostino, and Bucci, 1973).

\section{Case reports}

Case 1. A male, born at 35 weeks' gestation in a small community hospital. The mother had a small pelvis, and the presentation was a breech dorsal posterior. The delivery was by a midwife, who had to exert considerable traction to extract the baby. At birth the infant was cyanosed but breathing began spontaneously, and he remained normal for about 30 minutes after delivery. Thereafter, respiratory movements became increasingly distressed.

He was transferred to this unit at 6 hours of age, with a weight of $2640 \mathrm{~g}$, severe respiratory distress, and cyanosis in $100 \%$ oxygen. Deep inspiratory excursions of the chest, with marked withdrawal of the upper abdominal quadrants bilaterally, were conspicuous. Fine rales were heard over both lungs. The heart sounds, a rate of $150 / \mathrm{min}$, were not displaced. The abdomen was scaphoid, and the liver edge was palpable at the right costal margin. There was decreased muscular tone and movement of the upper limbs, a weak Moro response, absent suction and rooting reflexes, and a weak palmar and plantar grasp. At 7 hours of age, a chest $x$-ray showed marked decrease of expansion of lung fields, right diaphragm at the 6th rib and left diaphragm at the 7th intercostal space, atelectasis at both upper lobes, slight shift of the mediastinum to the left. This suggested phrenic nerve palsy (complete on the right side, and possibly present to some degree also on the left side).

An umbilical venous catheter was inserted up to the right atrial inlet. An umbilical arterial catheter was also introduced. After $22 \mathrm{mEq} \mathrm{NaHCO}_{3}$ had been administered because of severe combined acidosis, the acid-base status was normal but the arterial $\mathrm{Po}_{2}$ was relatively low in $100 \%$ oxygen (Table I, at 8 hours).

TABLE I

Case 1. Acid-base and oxygen determinations on arterial (umbilical) blood (see text)

\begin{tabular}{|c|c|c|c|c|c|}
\hline Age (hr) & 8 & 11 & 44 & $44 \cdot 5$ & 45 \\
\hline $\begin{array}{l}\mathrm{F}_{\mathrm{r}} \mathrm{O}_{2} \\
\mathrm{CPAP}\left(\mathrm{cm} \mathrm{H}_{2} \mathrm{O}\right) \\
\text { pH } \\
\text { Base excess } \\
\quad(\mathrm{mEq} / \mathrm{l} .) \\
\mathrm{PCO}_{2}(\mathrm{mmHg}) \\
\mathrm{PO}_{2}(\mathrm{mmHg}) \\
\mathrm{SaO}_{2}(\%)\end{array}$ & $\begin{array}{c}1 \cdot 0 \\
7 \cdot 34 \\
0 \\
46 \\
65 \\
92 \cdot 8\end{array}$ & $\begin{array}{c}1 \cdot 0 \\
+5 \\
7 \cdot 34 \\
+1 \\
48 \\
208 \\
100\end{array}$ & $\begin{array}{c}0 \cdot 4 \\
+5 \\
7 \cdot 40 \\
+5 \\
58 \\
126 \\
98 \cdot 5\end{array}$ & $\begin{array}{c}0 \cdot 4 \\
+3 \\
7 \cdot 47 \\
+5 \\
42 \\
124 \\
99 \cdot 5\end{array}$ & $\begin{array}{c}0 \cdot 4 \\
+3 \\
7 \cdot 44 \\
\\
+5 \\
48 \\
64 \\
94 \cdot 6\end{array}$ \\
\hline
\end{tabular}

The mean central venous pressure was $+8 /+9 \mathrm{~cm} \mathrm{H}_{2} \mathrm{O}$, with no respiratory oscillations seen on the oscilloscope even during the deepest inspirations. In view of the persistence of severe respiratory distress, CPAP breathing was started with the pressure of $5 \mathrm{~cm} \mathrm{H}_{2} \mathrm{O}$, and was immediately followed by improvement. Thoracic inspiratory efforts and abdominal inspiratory withdrawing decreased immediately. The rales cleared gradually over the next few hours. An arterial sample taken 30 minutes after the onset of CPAP breathing (Table I, at 11 hours) showed no acid-base changes and conspicuously increased $\mathrm{PO}_{2}$ with respect to the previous findings. The CVP rose to $+12 /+14 \mathrm{~cm} \mathrm{H}_{2} \mathrm{O}$ for about 30 minutes, but then returned to previous levels. A chest $x$-ray, taken at 26 hours of age, showed much improved lung expansion, and disappearance of pulmonary opacities and of the mediastinal shift.

Over the first 24 hours after the onset of CPAP breathing there was a gradual improvement of arterial $\mathrm{PO}_{2}$ and $p \mathrm{H}$ levels, and it was possible to keep $\mathrm{PaO}_{2}$ levels between 70 and $130 \mathrm{mmHg}$ by gradually decreasing the $\mathrm{F}_{2}$ to $0 \cdot 40-0 \cdot 45$. In the first week of life, attempts to discontinue or even to decrease the CPAP below $+5 \mathrm{~cm}$ $\mathrm{H}_{2} \mathrm{O}$ were immediately followed by a marked increase of respiratory distress. Arterial acid-base and oxygen 
values, taken during such an attempt on the second day of life, are shown in Table I (44, 44.5, and 45 hours).

The neurological examination taken on the second day of life showed marked deterioration of function of the upper limbs, i.e. signs of bilateral subtotal brachial palsy, with active movements only of the fingers. There was also hypotonia of the neck and trunk.

Total parenteral alimentation was given from the 2 nd to the 5th day of life. Thereafter, increasing amounts of human milk feeds were given by orogastric tube, and were well tolerated. Laboratory tests repeated during the first 10 days of life (including ECG; blood acid-base status; serum $\mathrm{Na}, \mathrm{K}, \mathrm{Cl}, \mathrm{Ca}, \mathrm{Mg}, \mathrm{P}$, total proteins, and bilirubin; blood glucose and blood urea nitrogen) were all normal, with the exception of a base excess between +7 and $+15 \mathrm{mEq} / \mathrm{l}$. (with $\mathrm{pH} 7 \cdot 40-7 \cdot 45$, and $\mathrm{PaCO}_{2}$ usually between 45 and $70 \mathrm{mmHg}$ ). This was interpreted as a metabolic alkalosis due to the particular amino acid mixture used in this unit for parenteral alimentation.

At 10 days it was possible to discontinue CPAP breathing. At this time fluoroscopy revealed paradoxical movements of the right diaphragm, and some reduced activity of the left diaphragm, with the right leaf at the 7 th $\mathrm{rib}$, and the left at the 8th intercostal space. Subsequent weight gain was satisfactory, and respiration became progressively normal. At 1 month of age withdrawing of the upper abdomen had disappeared. Neurological abnormalities had disappeared, with the exception of decreased tone and motility of the left shoulder and arm. The infant was discharged at 52 days weighing $3840 \mathrm{~g}$.

Case 2. A female, birthweight $1720 \mathrm{~g}$ at 39 weeks' gestation, born of a mother with a hypoplastic uterus. Amniotic fluid was meconium stained. Presentation was by breech, but no difficulties with the delivery were reported. At birth, colour and respiration were normal, but she was referred to our unit because of severe intrauterine growth retardation.

Examined at 3 hours, respiration was laboured, with marked thoracic and minimal abdominal inspiratory movements, a respiratory rate of $60 / \mathrm{min}$, and a Silverman's retraction score of 4 . Occasional rales were heard posteriorly. $30 \%$ oxygen was sufficient to relieve the cyanosis. There was also a proximal brachial palsy of the right arm. Chest $x$-ray showed decreased expansion of the right lung and a shift of the mediastinum to the left, with the right diaphragm at the 6 th rib, and the left diaphragm at the 9 th rib. Blood gas studies are given in Table II (13 hours). In the next 4 days respiratory distress gradually increased, and the $\mathrm{F}_{1} \mathrm{O}_{2}$ had to be increased gradually to 0.85 in order to maintain a $\mathrm{PaO}_{2}$ between 47 and $90 \mathrm{mmHg}$. On day 4 , a chest $x$-ray showed increased opacification of both lung fields, with right diaphragm at the 6th and left diaphragm at the 7th intercostal space, and with increased displacement of the mediastinum. ECG showed low voltage $T$ waves in all leads.

CPAP breathing by nasal cannula was started on the 5 th day of life, and was immediately followed by a
TABLE II

Case 2. Acid-base and oxygen determinations on arterial (radial) blood (see text)

\begin{tabular}{l|c|c|c|c}
\hline \multicolumn{1}{c|}{ Age (hr) } & 13 & 108 & 111 & 113 \\
\hline $\mathrm{F}_{\mathrm{1}} \mathrm{O}_{2}$ & $0 \cdot 30$ & $0 \cdot 85$ & 0.85 & 0.85 \\
$\mathrm{CPAP}\left(\mathrm{cm} \mathrm{H} \mathrm{H}_{2} \mathrm{O}\right)$ & - & - & +5 & +7 \\
$\mathrm{pH}$ & $7 \cdot 40$ & $7 \cdot 48$ & $7 \cdot 50$ & $7 \cdot 55$ \\
$\mathrm{Base}$ excess (mEq/1.) & $-7 \cdot 4$ & $+6 \cdot 0$ & $+5 \cdot 0$ & +6 \\
$\mathrm{PCO}_{2}(\mathrm{mmHg})$ & 24 & 41 & 38 & 30 \\
$\mathrm{Po}_{2}(\mathrm{mmHg})$ & 56 & 66 & 57 & 141 \\
$\mathrm{SaO}_{2}(\%)$ & $92 \cdot 8$ & $95 \cdot 8$ & 94.5 & $>99$ \\
& & & & \\
\hline
\end{tabular}

decrease of respiratory distress and tachycardia. Arterial blood values before and after CPAP are given in Table II (108-113 hours), showing no improvement of arterial oxygenation after 3 hours of CPAP breathing at $+5 \mathrm{~cm} \mathrm{H} \mathrm{H}_{2} \mathrm{O}$, but a marked rise in $\mathrm{PaO}_{2}$ after 2 hours of CPAP breathing at $+7 \mathrm{~cm} \mathrm{H}_{2} \mathrm{O}$. In the next 4 days CPAP was gradually decreased to $+3 \mathrm{~cm} \mathrm{H}_{2} \mathrm{O}$, and $\mathrm{F}_{\mathrm{I}} \mathrm{O}_{2}$ to $0 \cdot 48$, while $\mathrm{PaO}_{2}$ was maintained between 73 and 93 $\mathrm{mmHg}$. After 4 days of CPAP breathing, a chest $x$-ray showed almost normal lung fields and decreased mediastinal shift; on fluoroscopy, paradoxical movements of the right diaphragm and moderate contraction of the left diaphragm were seen. On day 10 CPAP breathing was discontinued, but the respiratory distress persisted, and CPAP was tried again on day 16. After 5 hours of CPAP breathing at $+4 \mathrm{~cm} \mathrm{H}$ and $\mathrm{SaO}_{2}$ rose slightly, but the infant became very restless and tachypnoeic, and CPAP breathing was discontinued.

In the first month of life weight gain was poor, but then improved. At age 60 days on chest $x$-ray the right diaphragm was at the 4 th intercostal space, and the mediastinal shift persisted. Oxygen was discontinued in the third month, and the infant was discharged. Tone and motility of the right upper limb were now normal.

\section{Discussion}

In both infants the diagnosis of right phrenic nerve palsy was established by the clinical and $x$-ray findings (and in Case 1 was also suggested by the history). In Case 1 clinical and $x$-ray findings suggested that initially the activity of the left diaphragm was also impaired. Respiratory failure developed rapidly in both patients, and was dramatically relieved by CPAP breathing. In Case 1 a gradual improvement occurred during and after CPAP breathing, and in the second month of life clinical and laboratory signs of respiratory insufficiency were no longer seen. In Case 2 the respiratory symptoms improved more slowly, and the phrenic nerve palsy persisted.

Respiratory function studies in neonatal diaphragmatic disorders have been performed by Murdock, Burrington, and Swyer (1971). In 10 newborns with congenital diaphragmatic hernia they found a marked increase of the alveolar-arterial $\mathbf{P o}_{2}$ 
gradient and $\mathrm{PaCO}_{2}$ levels generally within normal limits, and suggested that this defect was mostly due to intrapulmonary venous admixture. In adults with unilateral relaxation of the diaphragm and without associated pulmonary disease, Poppius, Varpela, and Korhonen (1969) found slightly increased dead-space ventilation and venous admixture, but no signs of asynchronous ventilation; however, one patient with bilateral involvement had abnormally low $\mathrm{PaO}_{2}$ and high $\mathrm{PaCO}_{2}$ levels, with dyspnoea at rest.

In Case 1, though other causes of increased central venous pressure could not be excluded, the high pressure in the right atrium suggested that intrapleural pressure was close to zero. This, and the marked decrease of lung expansion and transparency on chest film, indicated that lung volumes were much decreased and well below the 'closing volume' (Mansell, Bryan, and Levison, 1972) of several peripheral lung units, explaining the large alveolar-arterial $\mathrm{Po}_{2}$ gradient during high oxygen breathing. In both patients, breathing with a CPAP of 5 to $7 \mathrm{~cm} \mathrm{H}_{2} \mathrm{O}$ presumably restored a transpulmonary pressure gradient high enough to reopen part of these units.

Early neonatal death has occurred not uncommonly in phrenic nerve palsy, being usually attributed to pneumonia (Richard et al., 1957). However, in some patients dying in the early days of life (Keuth, 1971), as well as in one dying at the age of 47 days (France, 1954), massive atelectasis was the only postmortem finding, suggesting that lung collapse per se may cause death in some cases. Mechanical ventilation has been proposed in the treatment of early pulmonary failure in neonatal phrenic nerve palsy (Keuth, 1971). However, the present study indicates that, provided that a sufficient lung volume is maintained by the administration of transpulmonary pressure, spontaneous ventilation by still functioning respiratory muscles is adequate. CPAP breathing by nasal cannula appears to be a simple and effective way to manage these patients. It may allow spontaneous recovery of diaphragmatic function in some cases, or postponement of surgical plication of the diaphragm in others.

\section{Summary}

Two newborn infants with respiratory failure due to phrenic nerve palsy were treated with continuous positive pressure breathing applied by nasal cannula. Rapid improvement of clinical, $x$-ray, and arterial oxygen findings followed. Some weeks after suspension of the treatment, respiratory symptoms had disappeared in one patient, but persisted to a moderate degree in the other.

Supported in part by contract no. 71.02195 .73 of the National Research Council (C.N.R.).

We are indebted to Professor E. Agostoni for comments and criticism, and to Mr. Peter Wyer for help in the preparation of the manuscript.

\section{REFERENCES}

Caliumi-Pellegrini, G., Agostino, R., Orzalesi, M., Nodari, S. Marzetti, G., Savignoni, P. G., and Bucci, G. (1974). Twin nasal cannula for administration of continuous positive airway pressure to newborn infants. Archives of Disease in Childhood, $49,228$.

France, N. E. (1954). Unilateral diaphragmatic paralysis and Erb's palsy in the newborn. Archives of Disease in Childhood, 29, 357.

Keuth, U. (1971). Handbuch der Kinderheilkunde, Vol. 1, Part 2, p. 128. Ed. by H. Opitz and F. Schmid. Springer, Berlin.

Mansell, A., Bryan, C., and Levison, H. (1972). Airway closure in children. Fournal of Applied Physiology, 33, 711.

Murdock, A. I., Burrington, J. B., and Swyer, P. R. (1971), Alveolar to arterial oxygen tension difference and venous admixture in newly born infants with congenital diaphragmatic herniation through the foramen of Bochdalec. Biology of the Neonate, 17, 161.

Nodari, S., Agostino, R., and Bucci, G. (1973). Proper location of umbilical venous catheters by internal electrocardioscopy. Acta Paediatrica Scandinavica. 62, 492.

Orzalesi, M. M., Mendicini, M., Bucci, G., Scalamandrè, A., and Savignoni, P. G. (1967). Arterial oxygen studies in premature newborns with and without mild respiratory disorders. Archives of Disease in Childhood, 42, 174.

Poppius, H., Varpela, E., and Korhonen, O. (1969). Respiratory function and exercise tolerance in relaxation of the diaphragm. Scandinavian fournal of Respiratory Diseases, 50, 68.

Richard, J., Chevalier, V., Cappelle, R., Cavrot, E., Content, J., and Delforge, J. (1957). La paralysis diaphragmatique obstétricale. A propos de dix cas. Archives Françaises de Pédiatrie, 14, 563.

G. Bucci, ${ }^{\star}$ G. Marzetti, S. Picece-Bucci, S. NodARI, R. Agostino, and C. MoretTi

Institute of Paediatrics, University of Rome, Italy.

^Correspondence to Dr. G. Bucci, Clinica Pediatrica Università, Viale Regina Elena 324, 00161 Roma, Italy.

\section{Krabbe's globoid cell leucodystrophy with hydrocephalus}

Globoid cell leucodystrophy (GLD) is a rapidly fatal, hereditary neurological disorder of infants. Since Krabbe's first description in 1916, less than 100 cases have been reported. Mostly the reports have concerned single cases or a few sibs, with one noticeable exception (Hagberg et al., 1969).

Recently, specific enzyme deficiencies have been shown in various tissues (Andrews et al., 1971; Austin et al., 1970; Miyatake and Suzuki, 1972; Suzuki, Schneider, and Epstein, 1971; Suzuki and Suzuki, 1971) making a diagnosis possible before death by an assay of peripheral leucocytes from a patient, or even amniocytes from a fetus at risk. 